\title{
Nilai Pendidikan Karakter dalam Ungkapan Hikmah di SD se-Karesidenan Surakarta dan Pemanfaatannya di Masa Pandemi
}

\author{
Eko Purnomo \\ Pendidikan Bahasa dan Sastra Indonesia, Universitas Muhammadiyah Surakarta \\ A310170150@student.ums.ac.id \\ Agus Budi Wahyudi \\ Pendidikan Bahasa dan Sastra Indonesia, Universitas Muhammadiyah Surakarta \\ abw186@ums.ac.id
}

Naskah diterima: 20 Oktober 2020 | Disetujui: 20 November 2020 | Diterbitkan: 23 November 2020

\begin{abstract}
During the Covid-19 pandemic, child mischief conducts tend to somehow worrying, even in elementary school (SD) pupils. Whilst, posters containing wisdom expression posted on the walls of several schools in Surakarta region seems relevant to the issue. This research problematizes the value of religious character education contained in the expression of wisdom on the schools' walls, and its meaning as well as its function in this pandemic situation. This qualitative research aims to find various kinds of religious values on the posters in the schools and describes the meaning of those values. The source of research data is written language, namely the expression of wisdom which has religious value. Data collection techniques used are documentation (seeing) and observation techniques (noting). Consecutively, the data is then analyzed through the referential equivalent method and triangulation of data sources. As result, found that there are five religious sub-values, namely peace-loving, tolerance, self-esteem, friendship, and environmental care, that could be utilized by teachers in distance learning during the pandemic.
\end{abstract}

Keywords: character education, elementary school, expression of wisdom, religious values

\begin{abstract}
Abstrak
Selama pandemi Covid-19, perilaku kenakalan anak cenderung mengkhawatirkan, bahkan pada siswa Sekolah Dasar (SD). Sementara, poster yang berisi ungkapan kebijaksanaan yang ditempel di dinding beberapa sekolah di wilayah Surakarta tampaknya relevan dengan persoalan tersebut. Penelitian ini mengkaji nilai pendidikan karakter agama yang terkandung dalam ekspresi kearifan di dinding sekolah, dan maknanya serta fungsinya dalam situasi pandemi ini. Penelitian kualitatif ini bertujuan untuk menemukan berbagai macam nilai religius pada poster di sekolah dan mendeskripsikan makna dari nilai-nilai tersebut. Sumber data penelitian adalah bahasa tertulis yaitu ungkapan hikmah yang memiliki nilai religius. Teknik pengumpulan data yang digunakan adalah teknik dokumentasi (melihat) dan observasi (mencatat). Secara berurutan, data tersebut kemudian dianalisis melalui metode ekuivalen referensial dan triangulasi sumber data. Sebagai hasil, ditemui lima subnilai religius yaitu cinta damai, toleransi, percaya diri, persahabatan, dan mencintai lingkungan, yang dapat dimanfaatkan guru dalam proses pembelajaran jarak jauh di masa pandemi.
\end{abstract}

Kata Kunci: nilai religius, pendidikan karakter, Sekolah Dasar, ungkapan hikmah

2656-9779 @ 2020 The Author(s).

Published by Lembaga Penerbitan dan Publikasi Ilmiah Program Pascasarjana IAI Sunan Giri Ponorogo. This is an open access article under the CC BY-SA 4.0 license. DOI: 10.37680/qalamuna.v12i2.561 


\section{Pendahuluan}

Kualitas pendidikan karakter di Indonesia dari tahun ke tahun dipandang oleh sebagian kalangan kian mengalami penurunan. Penyimpangan perilaku di lingkungan sekolah dapat terjadi di kelas atau di luar kelas. Bukti empiris di lapangan menunjukkan bahwa generasi muda, hingga termasuk juga di dalamnya adalah siswa sekolah dasar, banyak melakukan kenakalan (Kemendikbud, dalam Apriani \& Wangid, 2015). Wijayanti \& Uswatun (2019) menyatakan bahwa tindak perundungan (bullying) tidak memandang usia pelaku maupun korban, bahkan di kalangan anak sekolah dasar (SD) pun banyak ditemukan kasus perundungan (bullying). Pendidikan karakter mendapatkan perhatian yang lebih sebagai antisipasi penurunan kualitas pendidikan karakter. Hal ini dapat diilustrasikan sebagai krisis moral multidimensi yang melanda bangsa Indonesia adalah sebagai perwujudan anak bangsa yang tidak mendengarkan hati nuraninya dalam berbuat di segala bidang (Wantu, 2020). Kertajaya (dalam Buchori, et. al, 2016) lebih lanjut menyatakan pula, bahwa pendidikan moral relevan pada masa sekarang untuk mengatasi krisis moral di negara Indonesia. Jadi, pendidikan karakter yang berkualitas penting untuk ditanamkan kepada peserta didik sejak dini agar generasi bangsa mendatang dapat menjadi cerdas secara akademik maupun non-akademik. Hal tersebut, diperkuat oleh Judiani (2010) yang menyatakan bahwa pendidikan karakter perlu untuk dipupuk sejak jenjang Sekolah Dasar (SD).

Salah satu strategi memupuk pendidikan karakter di usia SD yang paling sederhana adalah dengan memperkenalkan nilai ungkapan hikmah melalui poster yang dipajang di dinding gedung sekolah. Nilai-nilai karakter dalam ungkapan hikmah yang ada di sekolah dengan demikian merupakan upaya awal dalam menanamkan pendidikan karakter pada anak.

Ungkapan hikmah tersebut berpotensi meningkatkan nilai karakter religius bagi peserta didik. Adanya indikasi bahwa pembuat ungkapan hikmah tersebut sudah memiliki nilai-nilai karakter religius. Ungkapan hikmah terdiri atas dua kata, yaitu kata ungkapan dan kata hikmah. Kata ungkapan artinya sepadan dengan kata cetusan, ekspresi, letupan atau sederet kata adegium, aforisme, amsal, bidal, maksim, pepatah, peribahasa, perbahasaan, petitih, ibarat, misal, pengandaian, perumpamaan, dan idiom (Endarmoko, 2016). Sedangkan kata hikmah sepadan dengan kata hikmat. Artinya 'kebijaksanaan, petunjuk; amanat, contoh, iktibar, kiasan, makna, pelajaran, teladan; afwah, berkat, keampuhan, kesaktian, pestaka, tuah, olah kesucian' (Endarmoko, 2016). Ungkapan hikmah berkarakter religius ditandai dengan kandungan nilai akhlak yang baik dalam ungkapan. Sholihah \& Windy (2020) menyatakan bahwa akhlak menunjukkan baik buruknya sikap seseorang.

Namun demikian terdapat kelemahan dari penggunaan media poster yang berisi ungkapan hikmah untuk memupuk pendidikan karakter anak, terutama di masa pandemi yang mengharuskan anak untuk belajar secara daring. Pada situasi seperti ini, anak berada di rumah sehingga ungkapan hikmah yang tertempel di dinding sekolah tidak terbaca secara rutin. Berangkat dari permasalahan tersebut, penulis tertarik untuk melakukan penelitian ini.

Dalam kajian literatur, penulis menemukan bahwa Santoso, dkk. (2018) memang telah menerbitkan tulisan yang berjudul "Membangun Karakter Siswa Sekolah Dasar melalui Media Ungkapan Hikmah". Hasil penelitian tersebut menunjukkan bahwa isi pesan hikmah meliputi nasihat kultural dan nilai-nilai arif. Ungkapan hikmah dapat dijadikan sebagai sarana membangun karakter siswa SD. Penelitian Santoso, dkk. memiliki persamaan dengan penelitian ini yaitu 
keduanya menggunakan data berupa ungkapan hikmah. Perbedaan penelitian ini adalah objek kajian Santoso, dkk adalah isi yang terkandung dalam ungkapan hikmah, sedangkan objek kajian penelitian ini adalah nilai pendidikan karakter religius serta bagaimana pemanfaatannya dalam pembelajaran di masa pandemi Covid-19.

Penelitian relevan selanjutnya yaitu penelitian Rokhman, et.al. (2013) meneliti "Character Education For Golden Generation 2045 (National Character Building for Indonesian Golden Years)". Hasil penelitian Rokhman, et.al. yaitu pendidikan dianggap sebagai tempat terbaik untuk mempersiapkan agen perubahan bangsa yang membawa kemakmuran bagi sesama. Persamaan penelitian Rokhman, et.al dengan penelitian ini yaitu keduanya sama-sama mengkaji pendidikan karakter. Perbedaan penelitian yaitu Rokhman, et.al meneliti bagaimana pembudayaan pendidikan karakter melalui pendidikan, pendidikan tidak hanya sebagai transfer ilmu saja, tetapi sebagai media pendidikan karakter, sedangkan penelitian ini meneliti nilai pendidikan karakter dalam ungkapan hikmah di SD Se-Karesidenan Surakarta yang bermuatan karakter religius dalam menyampaikan pesan pada peserta didik.

\section{Karakter dan Pendidikan Karakter Religius}

Anderson (dalam Chowdhury, 2018) menyatakan bahwa karakter dapat didefinisikan sebagai keunggulan moral dan ketegasan. Seseorang dikatakan memiliki integritas apabila memiliki nilainilai moral dalam dirinya. Karakter yang baik terdiri dari kebajikan. Kebajikan adalah baik secara objektif kualitas manusia, seperti: kebijaksanaan, kejujuran, kebaikan, dan disiplin diri.

Karakter bukanlah sesuatu yang dapat diwariskan kepada orang lain, karakter mampu diubah, tidak seperti sidik jari yang menjadi bawaan sejak lahir yang tidak dapat berubah (Gunawan, 2012). Karakter merupakan cara berpikir dan berperilaku yang berbeda dari setiap individu (Samani \& Hariyanto, 2017). Karakter merupakan nilai perilaku manusia yang berhubungan dengan Tuhan, diri sendiri, sesama makhluk hidup yang berakal, serta perbuatan berdasarkan norma-norma yang berlaku dalam kehidupan bermasyarakat (Samani \& Hariyanto, 2017). Jadi, karakter merupakan sesuatu perilaku yang dapat diubah tergantung dengan individu masing-masing.

Pendidikan Karakter adalah bidang yang luas dan diperebutkan dengan berbagai ontologi, filosofi, dan tujuan yang mendorong berbagai intervensi berbasis sekolah (Hart, et.al, 2019). Pendidikan karakter adalah praktik pendidikan yang mendorong perkembangan karakter siswa. Karenanya, karakter didefinisikan sebagai seperangkat karakteristik psikologis yang memotivasi dan memungkinkan individu berfungsi sebagai agen moral yang kompeten untuk melakukan kebaikan di dunia (Berkowitz, 2011). Thomas Lickona (dalam Jeynes, 2017) menyatakan definisi pendidikan karakter yaitu usaha yang dilakukan dengan sengaja untuk melakukan kebaikan di dunia agar lebih baik. Sedangkan Pattaro (2016) menyatakan bahwa pendidikan karakter (sebagai bidang yang luas dalam pendidikan) mengacu pada bidang studi komprehensif. Istilah komprehensif ini mengacu pada teori dan karya berbasis penelitian yang menawarkan perspektif interdisipliner, menggambarkan dari disiplin ilmu pendidikan, psikologi, pedagogi, filsafat, dan sosiologi.

Pendidikan karakter mencakup persiapan siswa dan keterlibatan atau asosiasinya. Keterlibatan seperti itu membutuhkan kebajikan, seperti: kejujuran, kasih sayang, keterbukaan, dan mendukung perkembangan lebih lanjut (Peterson, 2020). Sedangkan menurut Liu (2014) bahwa pendidikan 
karakter berfokus pada inti pengajaran etika dan nilai-nilai kebajikan. Pendapat tersebut diperkuat Berkowitz (2011) yang mengatakan bahwa pendidikan karakter melibatkan pengembangan pelatihan dan kebiasaan yang diperlukan untuk hidup dan bekerja untuk dapat meningkatkan karakter siswa.

Kemdikbud (2017) menyebutkan bahwa nilai karakter religius merupakan hubungan manusia dengan Tuhannya. Wujudnya berupa pelaksanaan perintah Tuhannya, mengakui perbedaan agama, menjunjung tinggi sikap toleran dan mampu hidup damai antarpemeluk agama. Subnilai pendidikan karakter religius, antara lain: menghargai perbedaan agama dan kepercayaan, teguh pendirian, kerjasama antarpemeluk agama dan kepercayaan, cinta damai, ketulusan, toleransi, percaya diri, tidak memaksakan kehendak, mencintai lingkungan, dan persahabatan, melindungi yang kecil dan tersisih, serta anti perundungan dan kekerasan. Nilai-nilai karakter yang menjadi prinsip dasar pendidikan karakter banyak ditemukan di beberapa sumber, di antaranya nilai-nilai yang bersumber dari keteladanan Rasulullah yang terjewantahkan dalam sikap dan perilaku sehari-hari beliau, yakni shiddiq (jujur), amanah (dipercaya), tabligh (menyampaikan dengan transparan), dan fathanah (cerdas) (Hidayatullah \& Arsanti, 2018).

\section{Metode Penelitian}

Penelitian ini merupakan penelitian deskriptif kualitatif. Penelitian kualitatif karena data yang digunakan adalah kata-kata, tanpa adanya hitungan. Penelitian kualitatif disebut juga dengan penelitian interpretive (Sugiyono, 2015:14). Penelitian ini menggunakan teknik deskripsi sehingga penelitian ini termasuk dalam penelitian deskriptif kualitatif, karena data berupa kata-kata yang kemudian dianalisis dengan cara mendeskripsikan setiap data yang ada. Objek kajian penelitian adalah ungkapan hikmah. Sumber data penelitian berupa bahasa tulis yaitu ungkapan hikmah yang yang memiliki nilai religius yang terdapat di SD se-Karesidenan Surakarta. Teknik pengumpulan data yang digunakan teknik observasi, teknik simak dengan teknik lanjutan catat, teknik dokumentasi. Analisis data menggunakan metode padan referensial. Metode padan referensial digunakan untuk menentukan identitas satuan kebahasaan menurut referen yang ditunjuk (Sudaryanto, 2018). Teknik analisis data menggunakan triangulasi sumber data.

\section{Hasil dan Pembahasan}

Ungkapan hikmah yang ditempel di dinding SD se-Karesidenan Surakarta mengandung nilainilai pendidikan karakter religius. Nilai karakter tersebut dapat meningkatkan kualitas karakter peserta didik. Ungkapan hikmah berkarakter religius ditemukan dan berpotensi mengoptimalkan karakter peserta didik. Karakter religius adalah karakter yang berkaitan dengan Tuhan Yang Maha Esa. Seseorang dikatakan taat kepada Tuhan jika memiliki karakter religius yang baik. Pendidikan karakter religius merupakan bagaimana hubungan manusia dengan Tuhan. Manusia yang beriman adalah manusia yang memiliki karakter yang baik. Di bawah ini disajikan beberapa subnilai pendidikan karakter religius menurut Kemdikbud (2017) yang ditemukan dalam ungkapan hikmah di dinding SD se-Karesidenan Surakarta. 


\section{Cinta Damai}

Cinta damai adalah karakter yang tidak menginginkan keributan dan selalu tenteram. Sahlan dan Angga (dalam Chaer, 2016) menyatakan bahwa cinta damai adalah perkataan, perbuatan, sikap, maupun tindakan yang menyebabkan orang lain merasa senang dan aman atas kehadiran kita. Karakteristik insan cinta damai adalah karakter seseorang yang tidak akan pernah melakukan keributan dengan orang lain. Ciri cinta damai antara lain tidak pernah membuat keributan, tidak suka mencari masalah dengan orang lain, dan menjaga kerukunan antar insan.

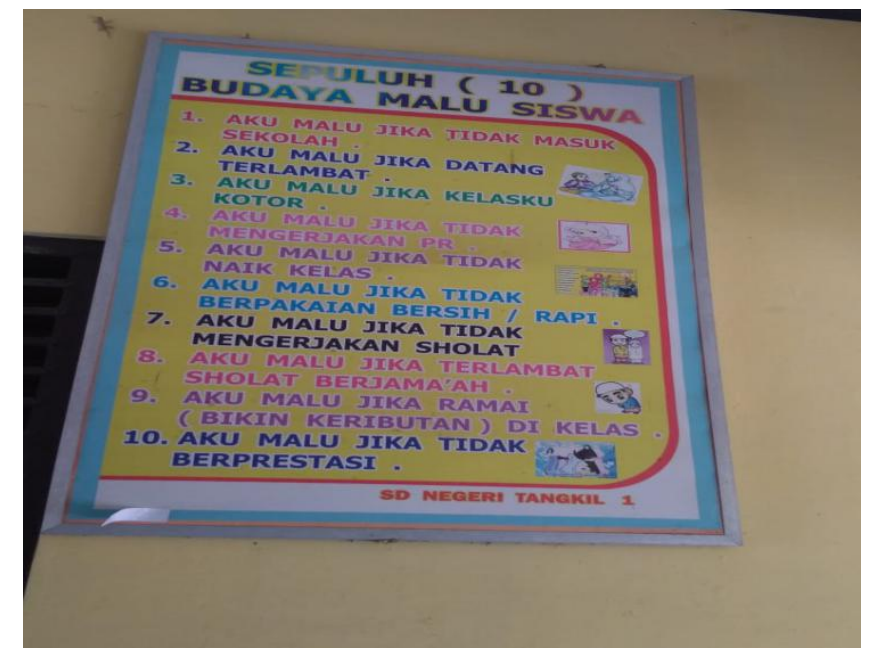

Gambar 1. Ungkapan hikmah di SDN 1 Tangkil Kabupaten Sragen

Ungkapan dalam Gambar 1 tersebut menyebutkan 10 budaya malu siswa. Ungkapan tersebut memiliki makna bahwa siswa yang berkarakter pasti akan malu, antara lain jika ramai di kelas, mengganggu teman yang sedang belajar, selalu melakukan keributan baik dengan teman maupun guru, dan sebagainya.

Individu maupun kelompok yang cinta damai menghargai perbedaan sehingga lebih menjaga perkataan, sikap, dan perbuatan dari hal-hal yang merugikan orang lain. Selain itu, individu maupun kelompok yang memiliki nilai cinta damai cenderung menghargai keberhasilan orang lain dan termotivasi melakukan hal-hal yang bermanfaat bagi masyarakat umum (Zubaedi, dalam Sari, dkk, 2019). Data dalam Gambar 1 ini mengandung nilai karakter religius subnilai cinta damai. Peserta didik dibudayakan sejak SD untuk malu, jika melakukan keributan. Malu jika ramai dan mengganggu teman merupakan relevansi dari nilai karakter religius subbab cinta damai.

\section{Toleransi}

Toleransi merupakan nilai pendidikan karakter yang menghargai perbedaan, baik perbedaan agama, suku, ras, dan lain sebagainya. Sikap toleransi ditanamkan sejak dini, terutama ketika anak sudah menginjak SD. Toleransi tidak berarti mencampuradukkan ajaran agama (Suharyanto, 2013), apalagi dalam konteks bangsa Indonesia yang merupakan bangsa bhinneka (beragam suku dan bangsa), maka toleransi harus menjadi sikap dalam kehidupan bersama. Di antara nilai luhur bangsa Indonesia untuk menjadi pemupuk moral adalah adanya Pancasila (Pahlevi, 2014) dan kekayaan 
Nilai Pendidikan Karakter dalam Ungkapan Hikmah di SD se-Karesidenan Surakarta dan Pemanfaatannya di Masa Pandemi | Eko Purnomo \& Agus Budi Wahyudi

khazanah budaya bangsa lainnya, seperti Reyog Ponorogo (Al Rosidin, 2019) yang juga mengandung nilai-nilai pendidikan karakter.

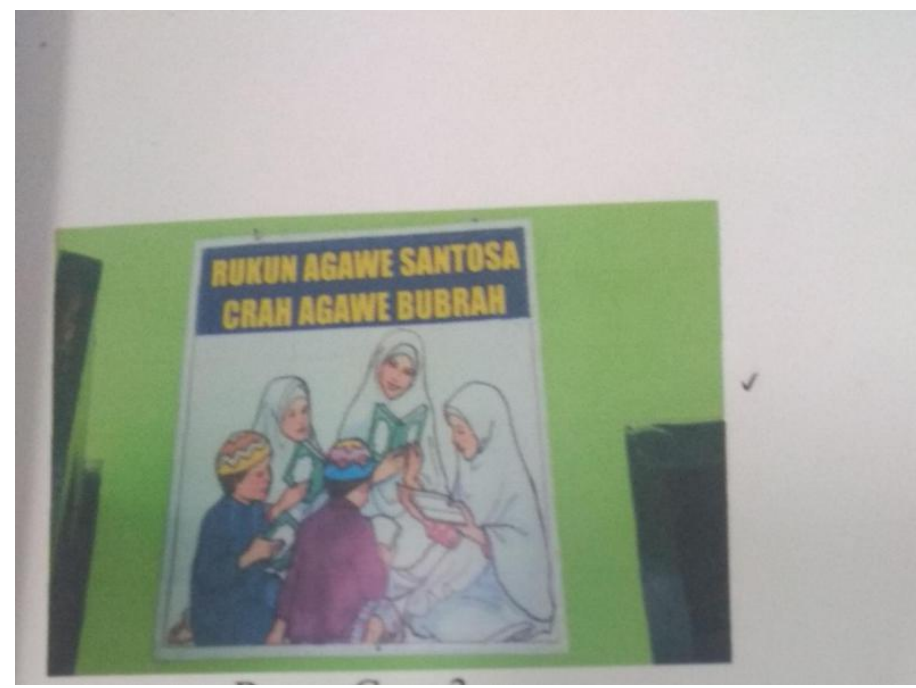

Gambar 2. Ungkapan Hikmah yang dipasang di SDN 03 Makam Haji, Kabupaten Sukoharjo

Ungkapan dalam Gambar 2 tersebut menuliskan kalimat Rukun agawe santosa crah agawe bubrah (Kerukunan akan mendatangkan kebaikan, pertengkaran akan menyebabkan kekacauan). Maknanya, bahwa dengan sikap kerukunan toleransi atau tidak membeda-bedakan dalam berteman dapat menghasilkan kebaikan dalam berteman. Adapun jika kita bertengkar dan membeda-bedakan teman, permusuhan pasti akan terjadi.

Ungkapan hikmah Gambar 2 mengandung nilai pendidikan karakter subnilai toleransi. Maknanya, berkehidupan tidak membeda-bedakan teman. Dengan toleransi akan menjadikan peserta didik yang unggul yang tidak mudah terprovokasi.

\section{Percaya Diri}

Percaya diri adalah karakter percaya terhadap diri sendiri. Percaya diri ditanamkan pada diri peserta didik agar tidak mudah terpengaruh dengan hal-hal negatif, karena pengaruh adanya arus globalisasi yang semakin mudah membuat peserta didik goyah pendirian.

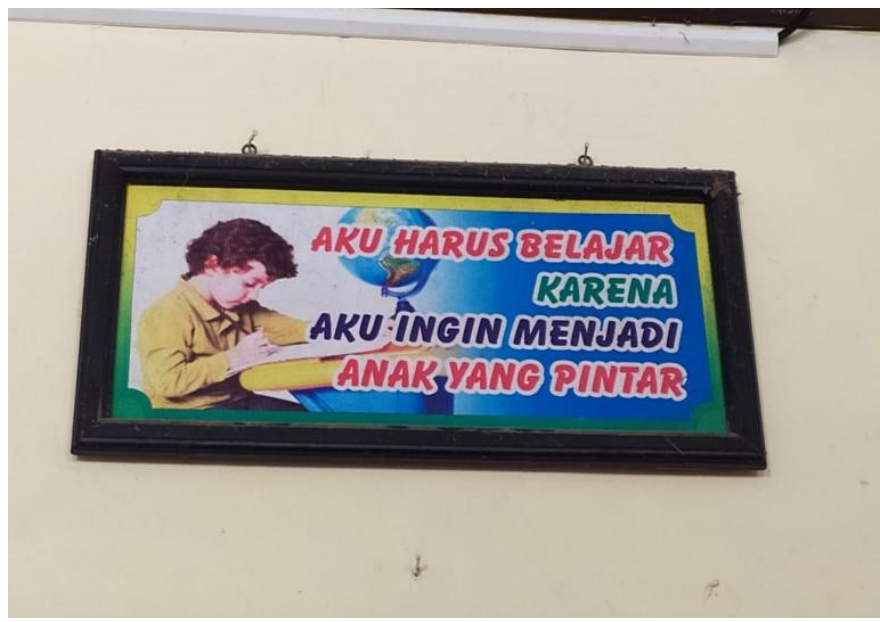

Gambar 3. Ungkapan hikmah yang dipasang di SDN Drajidan, Kabupaten Boyolali 
Ungkapan dalam Gambar 3 tersebut bertuliskan Aku harus belajar, karena aku ingin menjadi anak yang pintar dan bermakna bahwa orang yang selalu belajar akan mencapai apa yang diinginkan. Percaya bahwa dengan selalu belajar maka akan menjadi anak yang pintar.

Rasa percaya diri dapat tumbuh dalam diri peserta didik. Salirawati (2012) menyatakan rasa percaya diri mampu terbentuk ketika siswa mampu belajar mandiri tidak mencontek saat ujian. Selalu berusaha untuk menyelesaikan semua tugas dengan mandiri tanpa melihat jawaban dari teman untuk menumbuhkan rasa percaya diri.

Data di atas dengan selalu belajar (mencari ilmu) akan mampu menumbuhkan rasa percaya diri. Belajar termasuk dalam subnilai religius percaya diri. Noer (2014) menyimpulkan proses menuntut ilmu mampu sebagai sarana kita untuk menghapus dosa, karena dengan mencari ilmu merupakan langkah melakukan taubat yang mampu menghapuskan dosa serta kedzaliman yang telah dilakukan.

\section{Persahabatan}

Dalam berkehidupan sehari-hari manusia, termasuk juga anak-anak umumnya memerlukan sahabat untuk berkeluh kesah. Persahabatan sangat dibutuhkan apalagi bagi anak usia SD.

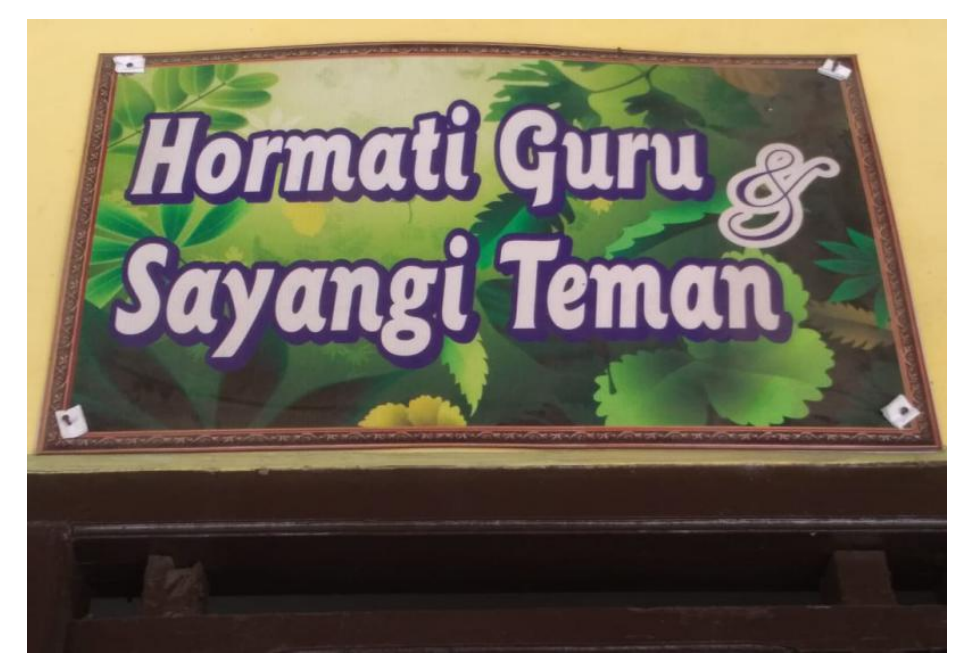

Gambar 4. Ungkapan hikmah yang dipasang di SDN 1 Tangkil, Kabupaten Sragen.

Ungkapan dalam Gambar 4 tersebut bertuliskan Hormati guru dan sayangi teman, bermakna bahwa anak didik harus selalu menyayangi orang tua, guru, serta semua teman-temannya. Sayang terhadap teman merupakan salah satu sikap persahabatan. Yusof \& Abdullah (2017) menyatakan bahwa dengan adab, umat Islam mampu hidup dengan aman damai saling menyayangi antara sesama manusia, terutama dalam mewujudkan ikatan persahabatan.

Data di atas termasuk dalam karakter religius dalam hal persahabatan. Persahabatan perlu ditingkatkan apalagi di masa pandemi covid-19 ini. Peserta didik sulit untuk bertemu dengan temantemannya sehingga nilai-nilai persahabatan akan berkurang. 
Nilai Pendidikan Karakter dalam Ungkapan Hikmah di SD se-Karesidenan Surakarta dan Pemanfaatannya di Masa Pandemi | Eko Purnomo \& Agus Budi Wahyudi

\section{Mencintai Lingkungan}

Lingkungan perlu dijaga agar tetap lestari. Mencintai lingkungan merupakan salah satu nilai karakter religius. Lingkungan yang bersih membuat kita nyaman. Allah SWT lebih menyukai lingkungan yang indah.

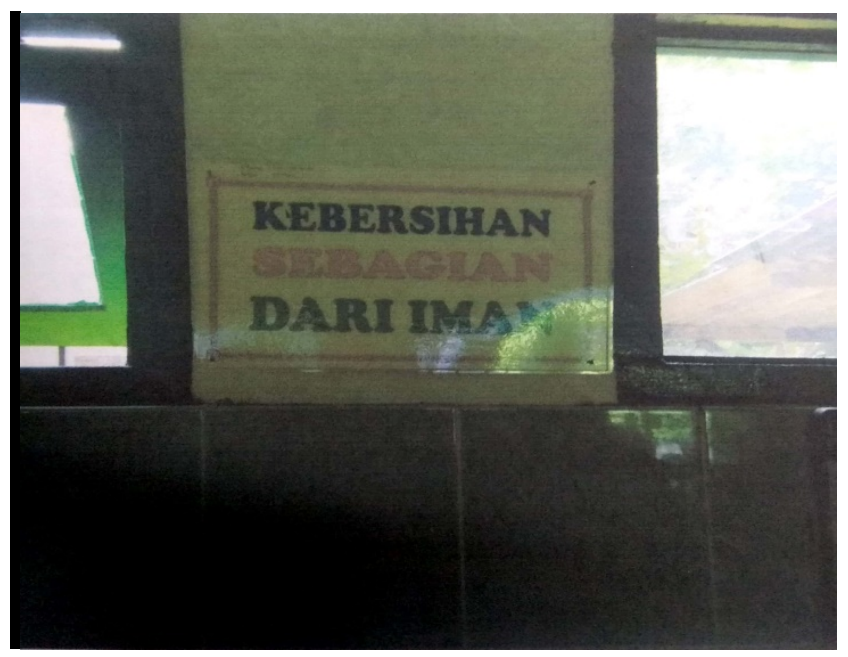

Gambar 5. Ungkapan hikmah yang dipasang di SDN 02 Gonilan, Kabupaten Sukoharjo.

Ungkapan dalam Gambar 5 tersebut bertuliskan Kebersihan sebagian dari iman dan bermakna bahwa dengan menjaga kebersihan merupakan sebagian dari iman. Dalam agama Islam jika seseorang mampu menjaga kebersihan Allah akan semakin sayang kepada hambanya. Allah itu indah, maka suka dengan keindahan dan kebersihan.

Ungkapan hikmah dalam gambar 5 ini termasuk dalam salah satu nilai religius dalam hal mencintai lingkungan. Menjaga kebersihan termasuk salah satu ciri mencintai lingkungan. Heriyanto \& Warsono (2019) menyatakan bahwa sekolah yang berbasis Islam seharusnya mampu mempunyai lingkungan yang bersih, karena pada ajaran agama Islam memiliki konsep tentang kebersihan yaitu kebersihan sebagian dari iman.

\section{Kesimpulan}

Kenakalan pada anak-anak dapat diantisipasi dengan menanamkan nilai pendidikan karakter religius. Ungkapan hikmah bernilai pendidikan karakter religius sudah ditempel di dinding sekolah SD se-Karesidenan Surakarta, tetapi karena adanya pandemi Covid-19 ini maka pembelajaran terpaksa dilaksanakan secara jarak jauh. Dilaksanakannya pembelajaran jarak jauh ini, berarti juga bahwa peserta didik tidak dapat membaca poster ungkapan hikmah yang telah dipasang di sekolah untuk kemudian mengaplikasikan nilai-nilai karakter religius dalam kehidupan sehari-hari. Ungkapan hikmah berkarakter religius yang ditemukan dalam ungkapan hikmah di SD seKaresidenan Surakarta terdapat lima subnilai religius yaitu cinta damai, toleransi, percaya diri, persahabatan, dan mencintai lingkungan. Oleh karena itu, ungkapan hikmah tersebut perlu disisipkan guru ke dalam proses pembelajaran yang diselenggarakan secara daring agar kontinuitas proses pendidikan karakter tidak terhenti. Guru dapat menyisipkan kata-kata yang terdapat dalam poster ungkapan hikmah ketika melakukan pembelajaran secara jarak jauh. 
Hal yang dapat menjadi saran dalam mengembangkan penelitian terhadap pendidikan karakter mendatang yaitu mengenai model penanaman ungkapan hikmah yang dilaksanakan secara intensif oleh guru-guru yang melaksanakan Pembelajaran Jarak Jauh pada masa pandemi Covid-19.

\section{Referensi}

Al Rosidin, N. (2019). NILAI - NILAI PENDIDIKAN KARAKTER DALAM KESENIAN REYOG PONOROGO. Al-Adabiya: Jurnal Kebudayaan Dan Keagamaan, 14(02), 195-215. https://doi.org/10.37680/adabiya.v14i02.210

Apriani, A., \& Wangid, M. (2015). PENGARUH SSP TEMATIK-INTEGRATIF TERHADAP KARAKTER DISIPLIN DAN TANGGUNG JAWAB SISWA KELAS III SD. Jurnal Prima Edukasia, 3(1), 12-25. doi: https://doi.org/10.21831/jpe.v3i1.4061

Arsanti, M. (2018). Pengembangan Bahan Ajar Mata Kuliah Penulisan Kreatif Bermuatan NilaiNilai Pendidikan Karakter Religius bagi Mahasiswa Prodi PBSI, FKIP, UNISSULA. KREDO: Jurnal Ilmiah Bahasa dan Sastra, 1(2), 69-88.https://doi.org/10.24176/kredo.v1i2.2107

Berkowitz, M. (2011). What Works in Values Education? International Journal of Educational Research, 50, 153-158. http://dx.doi.org/10.1016/j.ijer.2011.07.003.

Buchori, A., Setyosari, P., Dasna, I. W., \& Ulfa, S. (2016). Developing Character Building Learning Model Using Mobile Augmented Reality on Elementary School Student in Central Java. Global Journal of Pure and Applied Mathematics, 12(4), 3433-3444.

Chaer, M. (2017). Islam dan Pendidikan Cinta Damai. Istawa: Jurnal Pendidikan Islam, 2(1), 73-94. https://doi/10.24269/ijpi.v2i1.363

Chowdhury, M. (2018). Emphasizing Morals, Values, Ethics, and Character Education in Science Education and Science Teaching. MOJES: Malaysian Online Journal of Educational Sciences, 4(2),1-16. https://eric.ed.gov/?id=EJ1188220.

Endarmoko, E. (2016). Tesamoko Tesaurus Bahasa Indonesia. Jakarta: Gramedia.

Gunawan, H. (2012). Pendidikan Karakter. Bandung: Alfabeta 2.

Hart, P., Oliveira, G., \& Pike, M. (2019). Teaching Virtues Through Literature: Learning from the 'Narnian Virtues' Character Education Research. Journal of Beliefs \& Values, 1- 15. https://doi.org/10.1080/13617672.2019.1689544

Jeynes, W. (2019). A Meta-Analysis on the Relationship Between Character Education and Student Achievement and Behavioral Outcomes. Education and Urban Society, 51(1), 33-71. https://doi.org/10.1177/0013124517747681

Judiani, S. (2010). Implementasi Pendidikan Karakter di Sekolah Dasar melalui Penguatan Pelaksanaan Kurikulum. Jurnal pendidikan dan kebudayaan, 16(9), 280-289. https://doi.org/10.24832/jpnk.v16i9.519

Kemdikbud (2017). Penguatan Pendidikan Karakter Jadi Pintu Masuk Pembenahan Pendidikan Nasional. Diakses pada 23 Oktober, 2020 dari 
Nilai Pendidikan Karakter dalam Ungkapan Hikmah di SD se-Karesidenan Surakarta dan Pemanfaatannya di Masa Pandemi | Eko Purnomo \& Agus Budi Wahyudi

https://www.kemdikbud.go.id/main/blog/2017/07/penguatan-pendidikan-karakter-jadi-pintumasuk-pembenahan-pendidikan-nasional.

Liu, X. (2014). The Problem Of Character Education and Kohlberg's Moral Education: Critique From Dewey's Moral Deliberation. Philosophical Studies In Education ,Volume 45, pp 136145.

Noer, M. (2017). MENUNTUT ILMU SEBAGAI TRANSFORMASI PERUBAHAN PARADIGMA. QATHRUNÂ, $1(01), \quad 1 \quad-\quad 22 . \quad$ Retrieved from http://jurnal.uinbanten.ac.id/index.php/qathruna/article/view/243

Pahlevi, F. (2014). REAKTUALISASI PANCASILA SEBAGAI UPAYA PENINGKATAN KUALITAS PENDIDIKAN MORAL BANGSA INDONESIA. Al-Adabiya: Jurnal Kebudayaan Dan Keagamaan, 9, 21-44.

Pattaro, C. (2016). Character Education: Themes and Researches. An academic Literature Review. Italian Journal of Sociology of Education, 8(1), 6-30. doi: 10.14658/pupj-ijse-2016-1-2

Peterson, A. (2020). Character Education, the Individual and the Political, Journal of Moral Education, (49)2, 143-157. https://doi.org/10.1080/03057240.2019.1653270.

Rokhman, F., Syaifudin, A., \& Yuliati. (2014). Character Education for Golden Generation 2045 (National Character Building for Indonesian Golden Years). Procedia - Social and Behavioral Sciences, 141, 1161-1165. https://doi:10.1016/j.sbspro.2014.05.197

Salirawati, D. (2012). Percaya Diri, Keingintahuan, dan Berjiwa Wirausaha: Tiga Karakter Penting bagi Peserta Didik. Jurnal Pendidikan Karakter, 2(2), 213-224. https://doi.org/10.21831/jpk.v0i2.1305

Samani, M., \& Hariyanto. (2017). Konsep dan Model Pendidikan Karakter. Bandung: Remaja Rosdakarya.

Santoso, J., Sabardila, A., Wahyudi, A., Setiawaty, R., \& Kusmanto, H. (2018). Membangun Karakter Siswa Sekolah Dasar Melalui Media Ungkapan Hikmah. In Prosiding Seminar Nasional Al-Islam dan Kemuhammadiyahan.

Sari, T., Purwadi, P., \& Mujidin, M. (2020, January). Efektivitas Psikodrama Nilai Karakter Cinta Damai untuk Mengurangi Kecenderungan Agresi Siswa SMP Muhammadiyah " $X$ " Yogyakarta. In Prosiding Seminar Nasional Magister Psikologi Universitas Ahmad Dahlan (pp. 71-81). http://seminar.uad.ac.id/index.php/snmpuad/article/view/2993

Sholihah, A., \& Maulida, W. (2020). Pendidikan Islam sebagai Fondasi Pendidikan Karakter. QALAMUNA: Jurnal Pendidikan, Sosial, dan Agama, 12(1), 4958. https://doi.org/10.37680/qalamuna.v12i01.214.

Sudaryanto. 2018. Metode dan Aneka Teknik Analisis Bahasa. Yogyakarta: Duta Wacana University Press.

Sugiyono. 2015. Metode Penelitian Kuantitatif, Kualitatif dan R\&D. Bandung. Alfabeta.

Suharyanto, A. (2013). Peranan Pendidikan Kewarganegaraan dalam Membina Sikap Toleransi Antar Siswa. JPPUMA Jurnal Ilmu Pemerintahan dan Sosial Politik Universitas Medan Area, 1(2), 1-12. https://doi.org/10.31289/jppuma.v1i2.563. 
Wantu, H. (2020). Pendidikan Karakter Untuk Membentuk Moralitas Anak Bangsa. Irfani, 16(1), 18. https://doi.org/10.30603/ir.v16i1.1310

Wijayanti, C., \& Uswatun, A. (2019). Perangi Tindak Perundungan (Bullying) dengan Penanaman Pendidikan Karakter Sejak Dini Pada Peserta Didik Sekolah Dasar. In Prosiding Seminar Nasional Pagelaran Pendidikan Dasar Nasional (PPDN) 2019 (Vol. 1, No. 1, pp. 16-26). http://seminar.uad.ac.id/index.php/ppdn/article/view/1395

Yusof, A., \& Abdullah, M. (2017). Adab Unggul Islam dalam Persahabatan Antara Insan. Attarbawiy: Malaysian Online Journal of Education, 1(2), 102-112 